\title{
A soft computing scheme incorporating ANN and MOV energy in fault detection, classification and distance estimation of EHV transmission line with FSC
}

\author{
Piyush Khadke ${ }^{1 *}$, Nita Patne ${ }^{1}$, Arvind Singh ${ }^{1}$ and Gulab Shinde ${ }^{2}$
}

${ }^{*}$ Correspondence: piyushkhadke88@gmail.com

${ }^{1}$ Electrical Engineering Department, Visvesvaraya

National Institute of Technology, Shankar Nagar, Nagpur 440010, Maharashtra, India

Full list of author information is available at the end of the article

\begin{abstract}
In this article, a novel and accurate scheme for fault detection, classification and fault distance estimation for a fixed series compensated transmission line is proposed. The proposed scheme is based on artificial neural network (ANN) and metal oxide varistor (MOV) energy, employing Levenberg-Marquardt training algorithm. The novelty of this scheme is the use of MOV energy signals of fixed series capacitors (FSC) as input to train the ANN. Such approach has never been used in any earlier fault analysis algorithms in the last few decades. Proposed scheme uses only single end measurement energy signals of MOV in all the 3 phases over one cycle duration from the occurrence of a fault. Thereafter, these MOV energy signals are fed as input to ANN for fault distance estimation. Feasibility and reliability of the proposed scheme have been evaluated for all ten types of fault in test power system model at different fault inception angles over numerous fault locations. Real transmission system parameters of 3-phase 400 kV Wardha-Aurangabad transmission line (400 km) with 40 \% FSC at Power Grid Wardha Substation, India is considered for this research. Extensive simulation experiments show that the proposed scheme provides quite accurate results which demonstrate complete protection scheme with high accuracy, simplicity and robustness.
\end{abstract}

Keywords: Artificial neural network, Transmission lines, Power system faults, Fault location

\section{Background}

Modern power systems with ever increasing power demands require power with satisfactory standards of quality and economy with feasible cost cutting measures (Hor et al. 2010; Nurdin et al. 2012). In developing countries, the optimized use of transmission system investments is very important. Practical application of FSC has been found it as the suitable choice not only to achieve the desired power increment, but also to stabilize the two interconnected strong networks by reducing the connecting line impedance of the given corridor's transmission capacity (Oliveira 2008). In addition to this, FSC is the simplest and cost-effective solution of increasing the power transfer capability of a power system that has long (250 km or more) transmission lines (Oliveira 2008).

(c) The Author(s) 2016. This article is distributed under the terms of the Creative Commons Attribution 4.0 International License (http://creativecommons.org/licenses/by/4.0/), which permits unrestricted use, distribution, and reproduction in any medium, provided you give appropriate credit to the original author(s) and the source, provide a link to the Creative Commons license, and indicate if changes were made. 
Estimation of the impedance to the fault point is influenced by the series compensation (Vyas et al. 2014a, b). Series compensation affects the fault location estimation in an unpredictable manner. Most of the reactance-based topologies suffer from mal-operation under reach due to $\mathrm{DC}$ offset current. Also, these schemes require measurement from both ends if the transmission line is having two end sources. In addition, the problem gets worse if the overvoltage protection of a series capacitor starts to operate due to high fault currents introducing nonlinearities in the measurement (Hosny and Safiuddin 2009). All of these nonlinear behavior due to series capacitor and its protection contributes to the distortion in phase voltage and line current waveforms. So, false tripping and mal-operation of circuit breakers is dominant due to series compensation. Hence conventional impedance based protection systems are most likely to malfunction (Hosny and Safiuddin 2009).

Fault classification and fault location estimation increases system stability, reliability and availability. Accurate location of faults on overhead transmission lines for inspection maintenance purposes is of vital importance for expediting service restoration to reduce service outage time and operating costs. Accurate fault analysis with location estimation will surely improve overall transient stability and reduce the switching overvoltage in the power system. Therefore, the fault type classification and fault distance estimation have become very important aspects of protection of series compensated transmission line.

MOV energy signals are never implemented before in any of the earlier conventional fault classification and location estimation algorithms. In order to find some new solution, authors have considered a new measurement scheme on FSC side rather than conventional line side voltage and current measurement.

A bibliographical survey of relevant background, effect of series compensation on transmission line protection and protection efforts for series compensated line is presented in Vyas et al. (2014a). Various fault-location algorithms for series-compensated lines have been developed so far. They apply one-end (Hosny and Safiuddin 2009; Ray 2014; Ray et al. 2013; Parikh et al. 2008; Abdelaziz et al. 2005; Vyas et al. 2014b; Moravej et al. 2012) and two-end measurements (Izykowski et al. 2011; Rubeena et al. 2014; Ahsaee and Sadeh 2011; Kang et al. 2015; Eldin 2010; Hussain and Osman 2014; Al-Dabbagh and Kapuduwage 2005; Yusuff et al. 2011; Ma et al. 2015; Abdelaziz et al. 2013) for two-terminal lines. In general, the impedance-based approach is the mostly applied. Multilayer perceptron neural networks (MLPNN) based scheme with two neural networks to address fault classification and location is proposed in Hosny and Safiuddin (2009). Fault location by extreme learning machine with genetic algorithm based feature selection method is depicted in Ray (2014). Wavelet transform (WT) and wavelet packet transform (WPT) combining ANN method for fault distance estimation has been considered in Ray et al. (2013) while a combined wavelet-support vector machine (SVM) technique for fault zone identification in series compensated transmission line has been investigated in Parikh et al. (2008), Yusuff et al. (2011). Two approaches based on travelling waves and two level ANN for fault type classification and faulted phase selection of series compensated transmission lines have been proposed in Abdelaziz et al. (2005). A new approach based on hyperbolic S-transform for extracting useful features from the input signals and support vector regression for fault location is presented in Moravej et al. (2012). A more general case of unsynchronized measurements utilizing 
two subroutines for locating a fault has been presented in Izykowski et al. (2011). Direct Prony analysis and four-cycle discrete Fourier transform algorithm based new offline technique is proposed for accurate estimation of fault current and voltage phasors of the series compensated transmission system in Rubeena et al. (2014). In Eldin (2010), a new system with wavelet MRA coefficients for fault detection and classification and adaptive neuro-fuzzy inference system (ANFIS) to obtain accurate fault location has been studied. A generalized fault loop method using pre-fault PMU measurements is considered in algorithm (Al-Mohammed and Abido 2014). A fault direction estimation technique for a series compensated line using phase change in positive-sequence current and magnitude change in the positive-sequence voltage at fault is provided in Jena and Pradhan (2010). Detailed analysis of a new method for fault event detection and optimum relay coordination in wind farm using genetic algorithm is given in Perven et al. (2015). A new concept of integrated impedance based intelligent relaying for transmission line with TCSC is introduced in Jena and Samantaray (2015). The technique in Moravej et al. (2011) presents a new combined S-Transform and Logistic Model Tree techniques for fault classification and fault section identification in transmission system with TCSC. Both schemes in Jena and Samantaray (2015), Moravej et al. (2011) lack to give fault distance estimation. In Ray (2014), Ray et al. (2013), post fault one cycle voltage and current signals have been taken while in Parikh et al. (2008), Ma et al. (2015) post fault one cycle current signals have been considered. Post fault half cycle window signals are used in Vyas et al. (2014a, b), Yusuff et al. (2011).

ANN is powerful in pattern recognition, classification and generalization tool (Vyas et al. 2014a, b). Off-line data training is very useful feature of ANN. Immunity to noise, robustness and tolerance to fault are a few of the advantages of ANN over other pattern recognition tools. Nonlinearity and variations in system parameters will not seriously affect an ANN-based relay decision. So, various ANN-based algorithms have been investigated and implemented in power systems in recent years Jain et al. (2009).

In this research work, an equivalent model of $400 \mathrm{kV}$ Wardha-Aurangabad line $(400 \mathrm{~km})$ which is under construction with end buses and $40 \%$ fixed series capacitors at Wardha Substation end, i.e. relaying end with protection scheme has been developed based on the real time parameters of the actual installed system. This FSC is being installed at 1200/765/400/220 kV Wardha Substation, Power Grid, Western Region (WR)-I, India. Figure 1 shows the considered equivalent schematic of series compensated transmission line with two $400 \mathrm{kV}$ end buses as described above.

This paper presents the application of ANN for fault distance location in a double end fed single circuit transmission line. All the ten types of internal shunt faults using only one terminal data, i.e. mainly MOV energy signals from relaying end have been considered. These MOV energy signals are taken over only one cycle window from the inception of fault which makes this scheme rapid. The effects of varying fault type, fault location and fault inception angle have been studied.

At present, quadrilateral characteristic distance relays are used for distance protection of $400 \mathrm{kV}$ fixed series compensated transmission line and is reported to perform less accurate in estimating fault location distance. Line side voltage and current measurement get affected abruptly in series compensated line, whereas, MOV energy signals are 


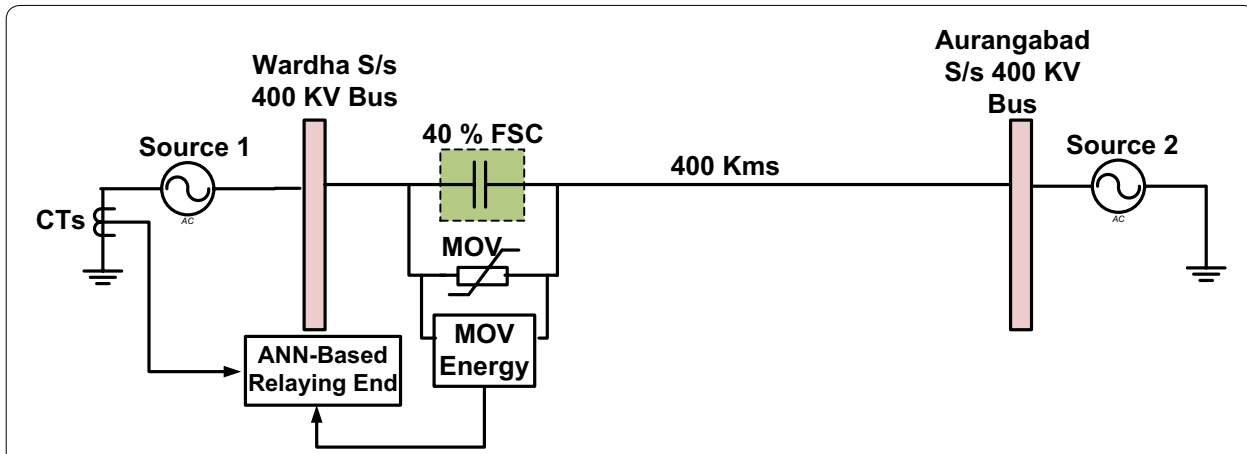

Fig. 1 Schematic of series compensated transmission line with FSC

not affected as compared to impedance measurement signals used in other distance protection schemes due to fixed series compensation.

The performance of the proposed scheme has been investigated by a number of offline tests for internal faults. Percent absolute error criterion is chosen to evaluate the proposed method performance. The simulation results show that all the ten types of internal faults can be correctly classified and located after one cycle from the inception of fault. In addition, the proposed scheme does not require a communication link to recover the remote end data. Such comprehensive work has not been reported earlier for fault classification and fault location estimation of fixed series compensated line using MOV energy signals of fixed series capacitors (FSC) as input to train the ANN with soft computing paradigm.

This paper is structured into 7 main sections; the first section is an introduction. In the "Working philosophy of FSC" section we discuss the basic protection scheme of FSC and in "System configuration and modeling" section system configuration and modeling in Matlab/Simulink with above mentioned real time system parameters is explained. Section "Implementation of ANN" focuses on ANN and learning rule implemented in this novel scheme while "Proposed algorithm" section introduces the detailed explanation of the proposed scheme of fault classification and fault location estimation with complete algorithm. Also, the details of training the ANN with MOV energy signals at various fault conditions to get the minimum error is explained in "Proposed algorithm" section. Section "Performance evaluation and results" presents the performance evaluation and simulation results of the proposed scheme in terms of percent absolute error. Finally, "Conclusions" section clarifies the extracted conclusions with this new superior proposed protection scheme of series compensated transmission line.

\section{Working philosophy of FSC}

Fixed series compensation has been utilized for many years with excellent results in AC power transmission. As show in Eqs. (1) and (2), series compensated transmission system will increase the active power transmission capability over the given corridor without affecting angular or voltage stability (Nurdin et al. 2012).

$$
\begin{aligned}
& \text { Power transmitted without FSC }=V s \times V r \times \sin \delta / X_{l} \\
& \text { Power transmitted with FSC }=V s \times V r \times \sin \delta /\left(X_{l}-X c\right)
\end{aligned}
$$




$$
\begin{aligned}
& V=f(P, Q) \\
& Q c=3 X_{c} I^{2}
\end{aligned}
$$

where, $\delta=$ Angular difference between voltages, $V s=$ Sending end voltage, $V r=$ Receiving end voltage, $X_{l}=$ Line reactance, $X c=$ Series capacitor reactance, $P, Q=$ Received active and reactive powers respectively, $Q_{c}=$ Reactive power of series capacitor

In Fig. 2, single-line scheme of actual installation of $400 \mathrm{kV} \mathrm{FSC} \mathrm{is} \mathrm{shown.} \mathrm{The} \mathrm{series}$ capacitor banks in FSC are protected with MOV and forced triggered spark gap protection (IEEE Standards 2013; Haddad et al. 2001; Ahmed et al. 2012). In case of a fault in the transmission line, high short circuit current will flow also through the capacitor bank which will increase the voltage across the capacitors. It is not economically feasible to design the capacitors to withstand very high voltages. Therefore the MOV having Zinc Oxide $(\mathrm{ZnO})$ discs are connected in parallel with the capacitor bank having highly non linear Voltage vs. Current characteristics. As long as the voltage across the capacitor is below the protective level, the MOV presents a very high resistance. Having the voltage across the capacitor terminals greater than the protective level, the MOV resistance becomes very low, and in turn, diverting a significant portion of the fault current away from the capacitor.

In case of external fault (fault outside the line section, where the series capacitor is located), the MOV is so designed that it will limit the voltage to the protective voltage level, keeping capacitor banks in circuit until the line circuit breakers in the external line will clear the fault.

In case of internal fault (fault inside the same line section, where the series capacitor bank is located), the forced triggered spark gap will bypass the MOV and the capacitor bank only when the fault current crosses the maximum current rating of the capacitor units (i.e. $3000 \mathrm{~A}$ in this case) and MOV dissipation energy level crosses its threshold limit (i.e. $15 \mathrm{MJ}$ ) thus protecting them. At the same time, the closing command is given to the bypass circuit breaker (BPCB) in order to protect and extinguish the spark gap.

The damping circuit helps to limit and dampen the discharge current of the capacitor bank in case the spark gap operates or the BPCB is closed. Current transformers

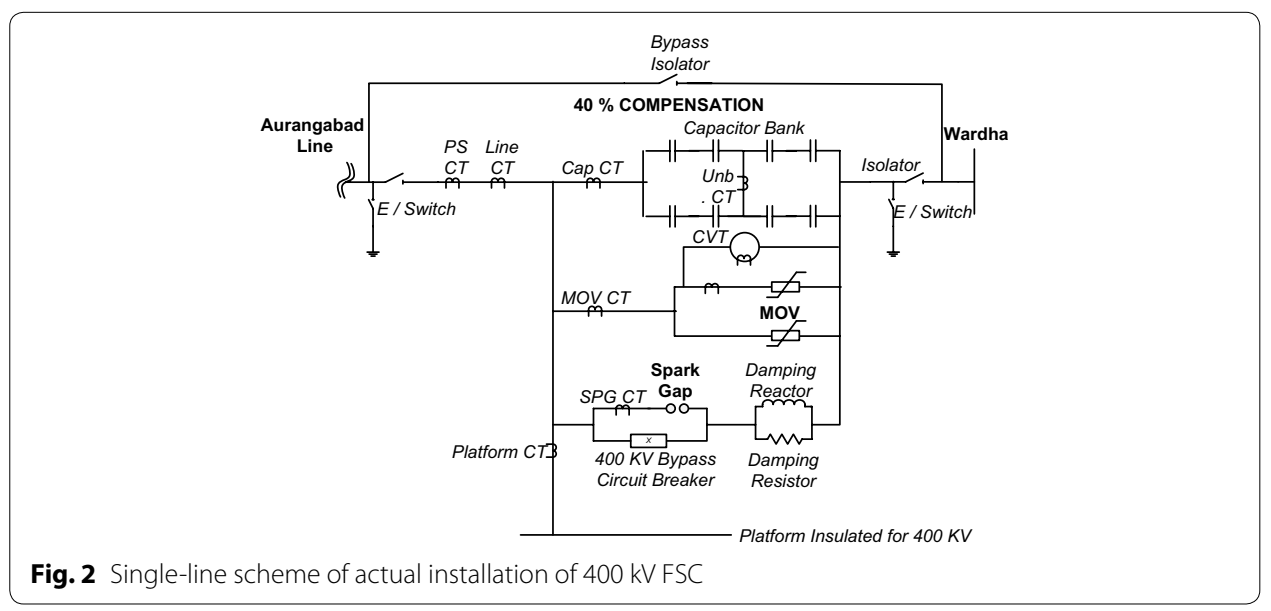


(CTs) are provided at different locations to measure the current for different protection systems. The two Isolators are used to connect the platform and platform equipments to the line or to isolate the platform and platform equipments from the line. The earth switches are used for earthing the platform and platform equipments, as soon as the platform is completely isolated from the line.

\section{System configuration and modeling}

Feasibility and reliability of the proposed scheme are investigated using fault data set of $400 \mathrm{kV}$ power system simulated in Matlab/Simulink software. Actual $400 \mathrm{kV}$ series compensated Wardha-Aurangabad transmission line $(400 \mathrm{~km})$ is considered for power system modeling. A two bus three phase $400 \mathrm{kV}, 50 \mathrm{~Hz}$ transmission system as shown in Fig. 2, has been simulated for the study of fault classification and location problem. The power system comprises two sources, $400 \mathrm{~km}$ transmission line and FSC with its associated protecting components. The transmission line is simulated using a distributed parameter line model. A discrete sampling frequency of $2 \mathrm{kHz}$ is used in simulation. The FSC installation is located at the Wardha substation end of the transmission line. $40 \%$ series compensation is achieved with this FSC. The transmission line parameters and other real time data at bus used for simulation are given in the "Appendix" section. Table 1 gives ratings of various components of FSC installed at Wardha Substation.

Total line reactance is $X_{l}=107.6 \Omega$. The capacitance of FSC, $C=73.96 \mu \mathrm{F}$ and capacitive reactance of FSC is $X c=43.04 \Omega$ which is $40 \%$ of Wardha-Aurangabad total line reactance. The capacitor bank is designed for maximum current rating of $3000 \mathrm{~A}$. The MCOV of MOV is kept $130 \mathrm{kV}$ in this case. Since the MOV is a non-linear resistive element and it has an energy dissipation limit, it is protected against excessive heat by an overload protection. The overload protection calculates the energy absorbed by the MOV and triggers a parallel air gap if the energy exceeds a threshold value i.e. $15 \mathrm{MJ}$ used in this study.

The MOV energy in the model is calculated in Eq. (5) over one cycle after inception of fault as,

$$
\text { MOV Energy }=\int(\text { Vmov } \times \text { Imov }) d t
$$

where, Vmov = Voltage across MOV, Imov = By-pass current through MOV.

In practice, these measurements are done with 0.2 accuracy class current and capacitive voltage transformers (CVT) which gives highly accurate measurements and saturation effects of measuring current and voltage transformers can be avoided.

Table 1 Ratings of various components of FSC

\begin{tabular}{lll}
\hline SI. no & Description & Rating \\
\hline 1 & Fixed compensation capacitor bank & $43.04 \Omega, 73.96 \mu F, 3000 \mathrm{~A}, 387.36 \mathrm{MVAR} /$ phase \\
2 & MOV for capacitor bank & $\mathrm{MCOV}=130 \mathrm{kV} \mathrm{rms}, E=15 \mathrm{MJ} /$ phase \\
3 & Spark gap & $\mathrm{FOV}=400 \mathrm{kV}$ \\
4 & Damping resistor & $10 \Omega$ \\
5 & Damping reactor & $700 \mu \mathrm{H}, 3000 \mathrm{~A}$ \\
6 & By-pass circuit breaker & $400 \mathrm{kV}, 3$ phase, SF6, 3150 A \\
\hline
\end{tabular}

MCOV maximum continuous operating voltage, FOV flash over voltage 


\section{Implementation of ANN}

ANN is a family of models motivated by biological neural networks which can be used to approximate the functions that can depend on a large number of inputs which are generally unknown and random. ANN is an efficient random function approximation tool (Vyas et al. 2014a, b). ANN can be powerfully used in online learning and large data set base applications. After appropriate mapping of inputs and outputs in ANN, the connections will enclose the non-linearity of the desired mapping.

The ANN structural design is set by experimenting different network cases and configurations with the number of inputs and the number of hidden layer neurons. A twolayer feed-forward network with sigmoid hidden neurons and linear output neurons is used here in order to solve multi-dimensional mapping problems. Figure 3 gives the general structure of ANN to be used. The input parameter for the ANN is per phase MOV energy, calculated over one cycle post fault. The output parameter of ANN is the fault distance from relaying point. For each type of faults, the number of hidden neurons in the hidden layer is selected based on the performance of the ANN for each case. For all the single line to ground (L-G) faults, the best performance is found with 3 hidden neurons in the hidden layer. For all the double line to ground ( $\mathrm{L}-\mathrm{L}-\mathrm{G}$ ) faults, 4 hidden neurons provided the best results, for all line to line (L-L) faults, 5 hidden neurons in hidden layer gave best results. Similarly, in case of three phase faults, 7 hidden neurons are found to give best performance. The selection of the number of hidden neurons w.r.t best performance is arrived after testing for numerous cases with increasing number of hidden neurons in hidden layer up to 50. The presented ANN has two layer feed forward network, one hidden layer with sigmoid transfer function and one output layer with linear transfer function purelin as depicted in Fig. 3.

Advantages of ANN over other classifiers are (1) it can be easily implemented in parallel architectures which reduces the processing time compared to other kind of algorithms, attaining comparable results, (2) it is able to obtain non-linear and complex relationships, (3) response is better and (4) it can handle large amount of data sets resulting in easy implementation in a digital relaying system.

It has been proven that approximation of any nonlinear function to arbitrary accuracy can be achieved by backpropagation learning with sufficient hidden layers. This makes backpropagation learning neural network a good investment for system modeling and signal prediction. The back-propagation learning rule is therefore used in perhaps $80-90 \%$ of practical applications. The most suitable training method for the algorithm of this research work is carried on with the Levenberg-Marquardt optimization technique. It is fast and has stable convergence. It has become a standard method for non-linear

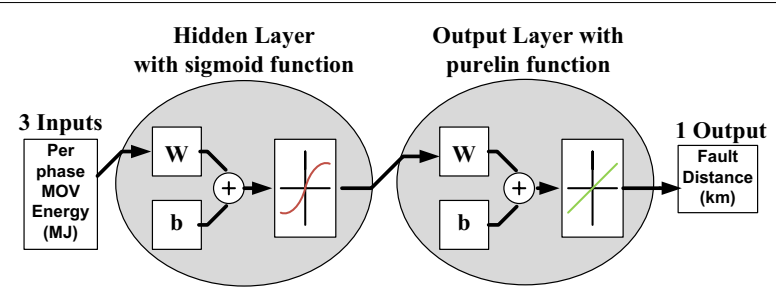

Fig. 3 Generalized structure of ANN 
least-squared problems and is widely adopted in various applications and streams for tackling with real time data-fitting problems.

\section{Proposed algorithm}

Series compensation affects the impedance estimation due to the fault and causes distortion of phase voltage and line current waveforms resulting in the fault location estimation in an unpredictable manner. Whereas, MOV energy signals are not affected as compared to impedance measurement signals used in protection schemes due to fixed series compensation. MOV energy signals are never implemented before in any of the earlier conventional fault classification and location estimation algorithms which make this online scheme distinctive. The use of online MOV energy signals with relaying end neutral current makes this scheme very easy and unique.

The proposed algorithm consists of two stages, namely fault detection with classification and accurate fault location estimation. Figure 4 shows the main structure of the proposed algorithm.

\section{Fault detection and classification}

Whenever there is an internal fault on the specified line, only respective phase MOV energy increases above threshold. This principle is used for the detection and

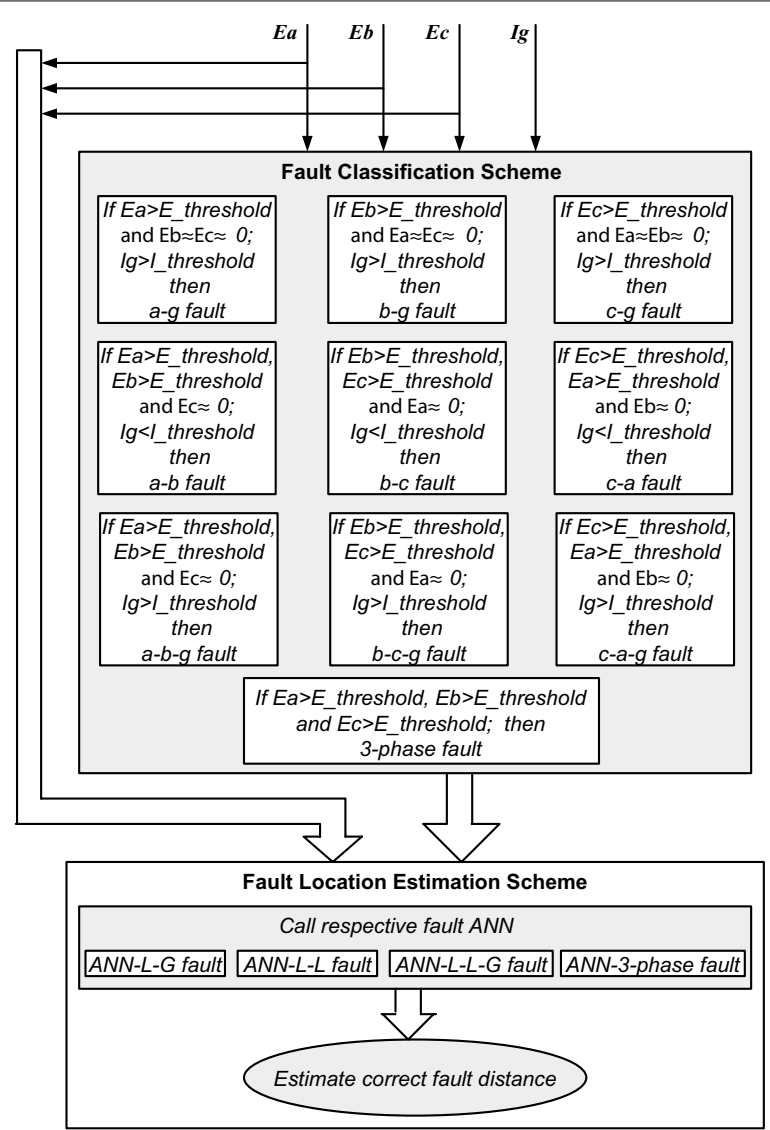

Fig. 4 Proposed algorithm 
classification of fault here and is illustrated in Result section. Provision of MOV energy measurement at FSC end is made. The MOV energy per phase is continuously monitored per cycle by the relay and as soon as the energy crosses the specified threshold value, the fault is detected and maximum value of MOV energy over one cycle from that instant is measured. $E a, E b, E c$ and $I g$ are the MOV energy signals per phase and neutral current at relaying end respectively. These signals are assumed to be passed through antialiasing filter. To classify the type of the fault, the magnitudes of these input signals are continuously compared with the predefined respective threshold values (which are given in Table 3) as follows:

1. If the magnitudes of MOV energy in only one phase and $I g$ are greater than the threshold, then the fault is classified as single phase to ground (L-G) fault.

2. If the magnitudes of MOV energy in any two phases and $I g$ are greater than the threshold while the magnitude of MOV energy in third phase is negligible, then the fault is classified as a double phase to ground ( $\mathrm{L}-\mathrm{L}-\mathrm{G})$ fault.

3. If the magnitudes of MOV energy in any two phases are greater than the threshold while the magnitude of MOV energy in third phase is negligible and $I g$ is less than the threshold, then the fault is classified as phase to phase (L-L) fault.

4. If the magnitudes of MOV energy in all the three phases are greater than the threshold simultaneously, then the fault is classified as 3-phase fault.

\section{Fault location estimation}

In this stage, the output of fault classification stage and MOV energy signals are used as input to the respective fault ANN to estimate accurate fault distance from relaying end. Four efficiently trained ANN networks for L-G, L-L, L-L-G and 3-Phase faults respectively are considered. Respective ANN is then activated according to the type of fault which then detects accurate fault location as the output of the proposed scheme as shown in algorithm Fig. 4. If there is an external fault, i.e. fault in another line behind the FSC then the main relay will recognize it as a reverse fault (as followed in industry at present) and the main relay will not let the proposed relay operate for such external fault proper logical coordination assigned. Further the fault point outside the line, it will have less impact on MOV energy and following this convention, the change in the MOV energy will not cross the set threshold value of the proposed algorithm and this relay will not operate for any external fault.

To design the best ANN, it is crucial to train it efficiently and correctly. The training sets are carefully chosen so that all fault conditions, i.e. different FIA and fault locations, are considered. The performance of this soft computation ANN scheme is then tested using random fault conditions in the training set. The approach adopted here is based on the Levenberg-Marquardt (Trainlm) optimization technique. To find the optimum values of the ANN parameters, input signals of $E a, E b$ and $E c$ corresponding to a particular fault condition are fed to the ANN and its output is compared with the desired output corresponding to that fault condition. The ANN is re-trained after each set of new fault conditions.

The expert system database is obtained by extensively simulating the system under normal and fault conditions of a transmission line during the investigation. The inputs 
are combined and also linked with the output, based on the expert system database to find the accurate ANN output. Accuracy of ANN outputs was also tested with various numbers of hidden layer neurons (up to 50 neurons). Best accuracy is found with 3 neurons in hidden layer for L-G fault, 4 neurons in hidden layer for L-L-G fault, 5 neurons in hidden layer for $\mathrm{L}-\mathrm{L}$ fault and 7 neurons in hidden layer for 3-phase fault. The various extensive fault conditions considered to train the ANN are explained in Performance evaluation and result section.

\section{Performance evaluation and results}

In order to test the validity of the proposed scheme, the model with the above mentioned system parameters is designed using Matlab/Simulink. Different fault types, such as single line to ground, double line to ground, double line and three-phase faults at different locations in front of the series compensator and different inception angles with realistic fault resistance are extensively investigated. To validate the robustness of the computational intelligent technique in the proposed algorithm, it is tested on a variety of fault cases as given in Table 2 and outputs are checked at random fault conditions for more than 9300 fault cases.

In most of the earlier algorithms, only few inception angles are considered. In order to get a more comprehensive vision on the effect of FIA on the proposed scheme, different inception angles over complete cycle are considered as listed in Table 2. For a particular distance, all the MOV energies simulated at above mentioned inception angles are averaged for simplicity. All such MOV energy values at various fault locations are given as input to train respective ANN network accurately. The threshold values used for the proposed scheme are calculated by simulating with severe fault conditions at the other end of relaying bus i.e. very near to $400 \mathrm{kV}$ Aurangabad substation bus. These threshold values found by precise simulations are depicted in Table 3 .

Table 2 FSC data generation for fault cases

\begin{tabular}{lllr}
\hline SI. no & Variation & Range & Cases \\
\hline 1 & Type of faults & $a-g, b-g, c-g, a-b-g, b-c-g, a-c-g, a-b, b-c, a-c, a-b-c$ & 10 \\
2 & MOV energy & All 3 phases & 3 \\
3 & Fault locations & $10-390 \mathrm{~km}$ (in step of $10 \mathrm{~km}$ ) & 39 \\
4 & Fault inception angle & $0^{\circ}, 45^{\circ}, 90^{\circ}, 135^{\circ}, 180^{\circ}, 225^{\circ}, 270^{\circ}$ and $315^{\circ}$ & 8 \\
& Total cases $=10 \times 3 \times 39 \times 8=9360$ \\
\hline
\end{tabular}

Table 3 Threshold values

\begin{tabular}{lll}
\hline Sl. no & Description & Threshold values \\
\hline 1 & MOV energy for L-G fault & $0.3 \mathrm{MJ}$ \\
2 & MOV energy for L-L fault & $4.2 \mathrm{MJ}$ \\
3 & MOV energy for L-L-G fault & $3.5 \mathrm{MJ}$ \\
4 & MOV energy for 3-phase fault & $5 \mathrm{MJ}$ \\
5 & Ig for L-G fault & $2000 \mathrm{~A}$ \\
6 & Ig for L-L fault & $100 \mathrm{~A}$ \\
7 & Ig for L-L-G fault & $1400 \mathrm{~A}$ \\
\hline
\end{tabular}


These threshold values are flexible and can be varied according to various system parameters and requirements of the particular transmission line. Even if there is involvement of ground due to another reason for the short time, threshold MOV energy value will not be crossed and proposed scheme will not treat it as a fault and the same has been checked.

An absolute error criterion is used in assessing the quality of the fault location schemes and the same is adopted in most of the referred work in the literature. So, the performance criterion for evaluating the fault location scheme was selected to be the percentage absolute error. The percentage absolute error is defined as Eq. (6),

$$
\frac{\mid \text { Actual fault distance }- \text { ANN fault distance } \mid}{(\text { Total line length })} \times 100
$$

Tables 4, 5, 6 and 7 show the ANN estimated fault locations for L-G (a-g), L-L (a-b), $\mathrm{L}-\mathrm{L}-\mathrm{G}(\mathrm{a}-\mathrm{b}-\mathrm{g})$ and 3-Phase $(\mathrm{a}-\mathrm{b}-\mathrm{c})$ faults respectively. In Tables 4, 5, 6 and 7 , the column with 'FIA' heading gives the inception angle at which the fault has been created. The column with 'Actual Fault Location' heading gives the fault location where the respective fault has been created on the transmission line in simulations. The column with 'ANN Fault Location' heading gives the estimated fault location which is the final output of trained ANN. As we have considered an absolute value for \% error calculation in the fault distance estimation, all the values in 'Abs. error' column in Tables 4, 5, 6 and 7 are positive (+ sign). The fault distance was calculated from trained ANN which was trained for all types of faults with input of MOV energy. After fault detection and classification, respective fault type ANN was called in the algorithm which estimated the fault location. ANN for $\mathrm{L}-\mathrm{G}$ fault was trained by one phase MOV energy inputs, ANN for $\mathrm{L}-\mathrm{L}-\mathrm{G}$ and $\mathrm{L}-\mathrm{L}$ faults were trained with two fault phase MOV energy inputs and ANN for 3-phase fault was trained with three phase's MOV energy input signals.

Table 4 Test results of ANN-based fault locator for a-g (L-G) fault

\begin{tabular}{lcccc}
\hline $\begin{array}{l}\text { MOV energy } \\
\text { a-ph (MJ) }\end{array}$ & FIA $\left(^{(}\right)$ & $\begin{array}{l}\text { Actual fault } \\
\text { location }(\mathbf{k m})\end{array}$ & $\begin{array}{l}\text { ANN fault } \\
\text { location }(\mathbf{k m})\end{array}$ & $\begin{array}{l}\text { Abs. error } \\
(\%)\end{array}$ \\
\hline 13.7300 & & 20 & 20.519 & 0.129 \\
13.4156 & 90 & 30 & 26.235 & 0.941 \\
13.3172 & 45 & 50 & 46.961 & 0.759 \\
13.2108 & 225 & 100 & 99.475 & 0.131 \\
12.7592 & 90 & 130 & 131.865 & 0.466 \\
10.2576 & 0 & 150 & 150.220 & 0.055 \\
8.4633 & 135 & 170 & 169.362 & 0.159 \\
6.4414 & 315 & 200 & 198.982 & 0.254 \\
4.4918 & 135 & 240 & 238.469 & 0.383 \\
2.9581 & 135 & 280 & 280.917 & 0.229 \\
2.1387 & 225 & 310 & 310.097 & 0.024 \\
1.6873 & 45 & 330 & 328.969 & 0.259 \\
1.0738 & 225 & 360 & 358.835 & 0.291 \\
0.7078 & 45 & 380 & 379.548 & 0.113 \\
\hline
\end{tabular}


Table 5 Test results of ANN-based fault locator for $a-b$ (L-L) fault

\begin{tabular}{llrccc}
\hline $\begin{array}{l}\text { MOV energy } \\
\text { a-ph (MJ) }\end{array}$ & $\begin{array}{l}\text { MOV energy } \\
\text { b-ph (MJ) }\end{array}$ & FIA $\left(^{(}\right)$ & $\begin{array}{l}\text { Actual fault } \\
\text { location }(\mathbf{k m})\end{array}$ & $\begin{array}{l}\text { ANN fault } \\
\text { location }(\mathbf{k m})\end{array}$ & $\begin{array}{l}\text { Abs. error } \\
(\%)\end{array}$ \\
\hline 14.2421 & 14.0606 & 45 & 20 & 19.110 & 0.223 \\
13.7765 & 13.9279 & 315 & 30 & 30.743 & 0.186 \\
13.5285 & 13.4685 & 45 & 50 & 47.259 & 0.685 \\
13.3872 & 13.3830 & 0 & 80 & 78.854 & 0.286 \\
13.3412 & 13.3794 & 180 & 100 & 95.783 & 1.054 \\
13.2796 & 13.3006 & 45 & 120 & 118.079 & 0.480 \\
13.2383 & 13.1856 & 0 & 200 & 200.987 & 0.246 \\
13.2290 & 13.1802 & 315 & 210 & 211.025 & 0.256 \\
13.1400 & 13.1790 & 180 & 240 & 244.489 & 1.122 \\
10.2597 & 11.2266 & 0 & 280 & 276.632 & 0.842 \\
8.2746 & 9.2286 & 135 & 310 & 316.215 & 1.554 \\
6.8715 & 7.4042 & 270 & 330 & 332.083 & 0.521 \\
5.9364 & 6.4356 & 90 & 360 & 356.125 & 0.969 \\
5.7576 & 6.5339 & 0 & 380 & 376.758 & 0.810 \\
\hline
\end{tabular}

Table 6 Test results of ANN-based fault locator for a-b-g (L-L-G) fault

\begin{tabular}{llrlll}
\hline $\begin{array}{l}\text { MOV energy } \\
\text { a-ph (MJ) }\end{array}$ & $\begin{array}{l}\text { MOV energy } \\
\text { b-ph }(\mathbf{M J})\end{array}$ & FIA $\left(^{(}\right)$ & $\begin{array}{l}\text { Actual fault } \\
\text { location }(\mathbf{k m})\end{array}$ & $\begin{array}{l}\text { ANN fault } \\
\text { location }(\mathbf{k m})\end{array}$ & $\begin{array}{l}\text { Abs. error } \\
(\%)\end{array}$ \\
\hline 14.3241 & 14.4362 & 45 & 20 & 23.041 & 0.760 \\
14.0472 & 13.7246 & 315 & 30 & 29.135 & 0.216 \\
13.4605 & 13.5245 & 225 & 50 & 52.025 & 0.506 \\
13.3956 & 13.3809 & 315 & 90 & 87.154 & 0.711 \\
13.3502 & 13.3528 & 45 & 100 & 99.118 & 0.220 \\
13.3489 & 13.3012 & 135 & 120 & 122.265 & 0.566 \\
13.2493 & 13.2646 & 90 & 150 & 149.099 & 0.225 \\
13.2002 & 13.2403 & 90 & 170 & 168.850 & 0.287 \\
13.1720 & 13.2105 & 135 & 200 & 194.404 & 1.399 \\
13.1466 & 13.1619 & 180 & 240 & 242.428 & 0.606 \\
10.4166 & 11.4689 & 45 & 280 & 273.366 & 1.658 \\
8.7512 & 9.8457 & 225 & 310 & 305.064 & 1.234 \\
7.4371 & 8.3886 & 135 & 330 & 330.146 & 0.036 \\
6.4755 & 7.6890 & 0 & 360 & 353.889 & 1.527 \\
5.1643 & 6.2444 & 0 & 380 & 377.318 & 0.670 \\
\hline
\end{tabular}

MOV energy measured at various locations at different inception angles was given as input to the trained ANN and output was given as soft computation estimated fault location by ANN. Outputs at randomly selected fault inception angles were checked and presented so as to get further clarified vision and more accuracy. The faults were created at 8th cycle. A realistic fault resistance of $0.1 \Omega$ was utilized considering the high severity of the faults and previously recorded real fault resistance values at the Wardha Substation.

Since the proposed scheme employed in this analysis is based on a distributed line model, exact transmission line parameters and results are accurate, this scheme can be implemented in a real fixed series compensated line. 
Table 7 Test results of ANN-based fault locator for a-b-c (3-phase) fault

\begin{tabular}{lllcccc}
\hline $\begin{array}{l}\text { MOV energy } \\
\text { a-ph (MJ) }\end{array}$ & $\begin{array}{l}\text { MOV energy } \\
\text { b-ph (MJ) }\end{array}$ & $\begin{array}{l}\text { MOV energy } \\
\text { c-ph (MJ) }\end{array}$ & FIA $\left(^{\circ}\right)$ & $\begin{array}{l}\text { Actual fault } \\
\text { location }(\mathbf{k m})\end{array}$ & $\begin{array}{l}\text { ANN fault } \\
\text { location (km) }\end{array}$ & $\begin{array}{l}\text { Abs. error } \\
(\%)\end{array}$ \\
\hline 14.6019 & 14.9586 & 14.0781 & 45 & 20 & 20.767 & 0.192 \\
13.7642 & 13.7174 & 14.0401 & 90 & 40 & 37.319 & 0.670 \\
13.6367 & 13.5339 & 13.8629 & 270 & 50 & 49.129 & 0.217 \\
13.4283 & 13.4839 & 13.3938 & 225 & 70 & 72.997 & 0.749 \\
13.4112 & 13.4025 & 13.3124 & 90 & 100 & 98.142 & 0.464 \\
13.3317 & 13.3024 & 13.2847 & 0 & 130 & 125.238 & 1.190 \\
13.2924 & 13.2707 & 13.2742 & 270 & 150 & 143.380 & 1.654 \\
13.2509 & 13.2450 & 13.2677 & 180 & 170 & 174.765 & 1.191 \\
13.1822 & 13.2299 & 13.2264 & 225 & 210 & 214.327 & 1.082 \\
10.3153 & 9.6280 & 12.5491 & 315 & 300 & 307.514 & 1.878 \\
7.8287 & 7.2297 & 9.8042 & 135 & 350 & 358.165 & 2.041 \\
7.6658 & 9.2136 & 6.2101 & 45 & 370 & 373.314 & 0.828 \\
7.2897 & 8.7731 & 5.8070 & 45 & 380 & 381.924 & 0.481 \\
\hline
\end{tabular}

Figure 5 shows simulation results of phase-a capacitor voltage with MOV Energies in a, b and c phases, respectively, for an internal a-b (L-L) fault on $400 \mathrm{kV}$ WardhaAurangabad line at $25 \mathrm{~km}$ from Wardha substation relaying end. It was seen in Fig. 5, as soon as the internal faults occur, MOV started conducting thus bypassing and protecting the series capacitor banks. For a-b phase to phase fault in Fig. 5, it was seen that the magnitudes of MOV energy in only phase-a and phase-b were increased above the threshold value while the magnitude of phase-c MOV energy was found nearly zero. The same principle was used in fault classification method of this scheme as explained in Proposed Algorithm section.

The FSC protection scheme was found working effectively for all the fault simulations performed. Evidently, the design settings for FSC were found correct. At various
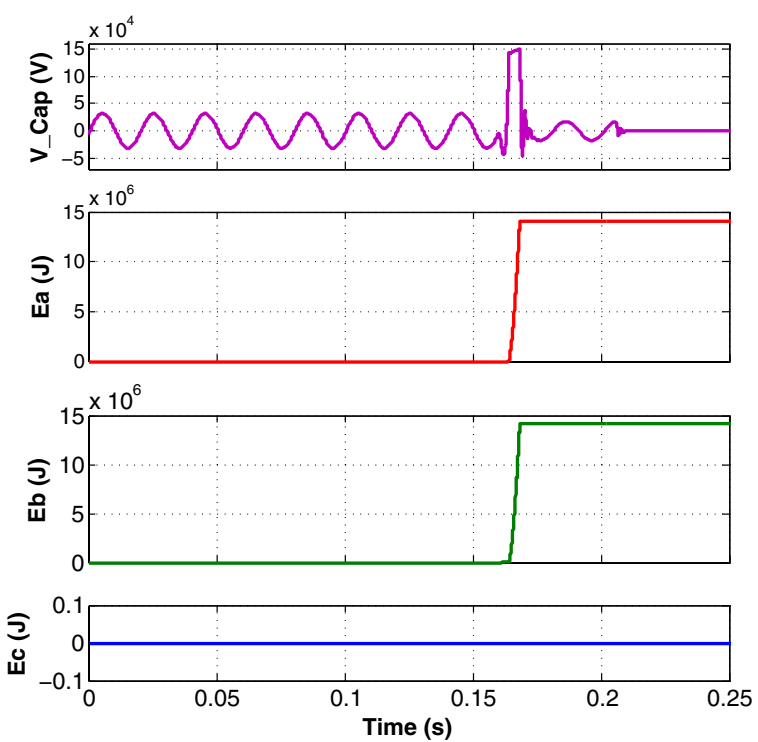

Fig. 5 a-Phase capacitor voltage, per phase MOV Energy in for an internal a-b fault 
locations, different types of faults were tested to find out the maximum deviation of the ANN estimated distance measured from the relay location, from the actual fault location. All the absolute errors were found to be well within $2 \%$. Tabulated results show that the soft computation technique of ANN captures the nonlinear relationship of input signals properly as evidenced by absolute error calculations. It can easily be seen from all the tables that the scheme is robust and accurate for varying fault conditions.

Fault classification accuracy aspect of the proposed algorithm has been compared with some of the methods in the literature in Table 8. Also, Fault location \% absolute error aspect comparison of the proposed algorithm w.r.t fault location of other schemes is presented in Table 9.

The overall superiority of the proposed algorithm is stated as follows:

- This algorithm requires only local per phase MOV energy measurement which is easily available at substation end.

- It does not need any feature extraction process from input signals which is mostly used in other algorithms in literature and hence the computational burden is reduced.

- No need of other end measurement, i.e. synchronized or unsynchronized data. So, the two end communication delay problems are avoided and cost is saved.

- MOV energy signals are not much affected as compared to impedance measurement signals used in other distance protection schemes due to fixed series compensation.

- The system considered in the proposed algorithm is modeled using real $400 \mathrm{kV}$ grid parameters.

\section{Conclusions}

A new online ANN-MOV energy based accurate scheme for fault detection, classification and fault location estimation in a series compensated transmission line has been proposed. The proposed algorithm provides a novel method for accurately estimating the fault location using only one end measurement where the FSC is installed. This novel

Table 8 Fault classification comparision

\begin{tabular}{lll}
\hline References & FIA range $\left(^{\circ}\right)$ & $\begin{array}{l}\text { Fault classification } \\
\text { accuracy (\%) }\end{array}$ \\
\hline Parikh et al. $(2008)$ & $0-115$ & 93.92 \\
Vyas et al. $(2014 \mathrm{a}, \mathrm{b})$ & $0-85$ & 99.39 \\
Moravej et al. $(2012)$ & $0-360$ & 99.21 \\
Proposed method & $0-360$ & 100 \\
\hline
\end{tabular}

Table 9 Fault Location Comparitive analysis

\begin{tabular}{llll}
\hline References & FIA range $\left(^{\circ}\right)$ & $\begin{array}{l}\text { Compensated } \\
\text { (yes/no) }\end{array}$ & $\begin{array}{l}\text { Max. Abs. } \\
\text { error (\%) }\end{array}$ \\
\hline Al-Mohammed and Abido (2014) & $0-150$ & Yes & $>2$ \\
Jain et al. (2009) & $0-90$ & No & 2.6 \\
Reddy and Mohanta (2008) & $0-180$ & No & 6 \\
Reddy and Mohanta (2007) & $0-180$ & No & 6.5 \\
Meyar-Naimi (2012) & Not specified & Yes & 10 \\
Proposed method & $0-360$ & Yes & $<2$ \\
\hline
\end{tabular}


scheme proves that it suits well in such fixed series compensated transmission system for complete protection application. The proposed algorithm has been suggested to the competent testing authority at the substation and the same has agreed to test run the algorithm with real time fault data during test commissioning.

The proposed scheme requires measurement data of MOV energy over only a short duration of post fault to classify and estimate the location of fault accurately. This fault location scheme gives estimates for fault distances which are well within the $2 \%$ error margin with proposed high accuracy 0.2 class measuring devices mentioned. The proposed online scheme, with simplicity, high accuracy and fast performance, is a smart investment for power system protection application. Thus, this ANN based scheme is proposed as a potential solution to detect, classify and locate faults accurately in $400 \mathrm{kV}$ series compensated line.

\section{Authors' contributions}

PK conceived the idea behind the proposed technique. AS participated in its design and modeling. GS and NP provided the real system parameters and testing platform. All the authors helped in drafting the manuscript. All authors read and approved the final manuscript.

Author details

1 Electrical Engineering Department, Visvesvaraya National Institute of Technology, Shankar Nagar, Nagpur 440010, Maharashtra, India. ${ }^{2}$ Power Grid Corporation of India Ltd., 1200/765/400/220 kV Wardha Substation of Power Grid Corporation of India Ltd., Deoli, Wardha 442101, Maharashtra, India.

\section{Acknowledgements}

The authors would like to thank Electrical Engineering Department., Visvesvaraya National Institute of Technology, Nagpur (India) for providing required research infrastructure for this project and Power Grid Corporation of India Ltd., WR-I for providing the necessary data as well as technical expertise for the same.

\section{Competing interests}

The authors declare that they have no competing interests.

\section{Appendix}

Transmission line parameters:

- Series compensation degree-40 \%

- Line length-400 km

- Conductor type-quad aluminium conductor steel reinforced (ACSR) Moose

- Thermal limit of quad Moose conductor-3000 A

- $X_{l}=91.85 \Omega$ (line reactance)

- $R_{1}=0.0146 \Omega / \mathrm{km}, X_{1}=0.2530 \Omega / \mathrm{km}, B_{1}=4.5777$ micro-mho $/ \mathrm{km}$ (positive sequence values)

- $R_{0}=0.2479 \Omega / \mathrm{km}, X_{0}=1.0001 \Omega / \mathrm{km}, B_{0}=2.6345 \mathrm{micro}-\mathrm{mho} / \mathrm{km}$ (zero sequence values)

Real time data for Simulation:

- Bus Voltage level-400 kV

- Fault MVA level-2.45 GVA

- Frequency-50 $\mathrm{Hz}$

- Total MOV columns in parallel-5 + 1 hot spare

- Reference current per MOV column-500 A

Received: 8 June 2016 Accepted: 13 October 2016

Published online: 21 October 2016 


\section{References}

Abdelaziz A, Ibrahim A, Mansour M, Talaat H (2005) Modern approaches for protection of series compensated transmission line. Electr Power Syst Res 75(1):85-98

Abdelaziz A, Mekhamer S, Ezzat M (2013) Fault location of uncompensated/series-compensated lines using two-end synchronized measurements. Electr Power Compon Syst 41(7):693-715

Ahmed A, Singh A, Dambhare S (2012) New modified first zone algorithm for transmission lines with series compensators. In: 2012 Fifth Power India conference. IEEE, pp 1-5

Ahsaee M, Sadeh J (2011) A novel fault-location algorithm for long transmission lines compensated by series FACTS devices. IEEE Trans Power Deliv 26(4):2299-2308

Al-Dabbagh M, Kapuduwage S (2005) Using instantaneous values for estimating fault locations on series compensated transmission lines. Electr Power Syst Res 76:25-32

Al-Mohammed A, Abido M (2014) A fully adaptive PMU-based fault location algorithm for series-compensated lines. IEEE Trans Power Syst 29(5):2129-2137

Eldin T (2010) Fault location for a series compensated transmission line based on wavelet transform and an adaptive neuro-fuzzy inference system. In: 2010 electric power quality and supply reliability conference (PQ). IEEE, pp 229-236

Haddad A, German D, Waters R, Abdul-Malek A (2001) Co-ordination of spark-gap protection with zinc-oxide surge arresters. Proc IEE Gener Transm Distrib 148(1):21-28

Hor C, Finn J, Thumm G, Mortimer S (2010) Introducing series compensation in the UK transmission network. In: 2011 international conference on $\mathrm{AC}$ and DC power transmission. IET, pp 1-5

Hosny A, Safiuddin M (2009) ANN-based protection system for controllable series-compensated transmission lines. In: 2009 IEEE/PES power systems conference and exposition, pp 1-6

Hussain S, Osman A (2014) Fault location on series and shunt compensated lines using unsynchronized measurements. Elect Power Syst Res 116:166-173

IEEE Standards (2013) IEEE approved draft guide for the functional specification of fixed transmission series capacitor banks for transmission system applications, July 2013

Izykowski J, Rosolowski E, Balcerek P, Fulczyk M, Saha M (2011) Fault location on double-circuit series-compensated lines using two-end unsynchronized measurements. IEEE Trans Power Deliv 26(4):2072-2080

Jain A, Thoke A, Patel R (2009) Double circuit transmission line fault distance location using artificial neural network. In: 2009 world congress on nature \& biologically inspired computing. IEEE, pp 13-18

Jena P, Pradhan A (2010) A positive-sequence directional relaying algorithm for series-compensated line. IEEE Trans Power Deliv 25(4):2288-2298

Jena M, Samantaray S (2015) Real time digital simulator implementation of data-mining-based integrated impedance relay for compensated lines. Int Trans Electr Energy Syst 25(7):1381-1396

Kang N, Chen J, Liao Y (2015) A fault-location algorithm for series-compensated double-circuit transmission lines using the distributed parameter line model. IEEE Trans Power Deliv 30(1):360-367

Ma J, Ma W, Zhu X, Gao X, Li Y, Wang X, Wang Z, Yang Q (2015) A novel fault phase selection scheme utilizing fault phase selection factors. Electr Power Compon Syst 43(5):491-507

Meyar-Naimi H (2012) A new fuzzy fault locator for series compensated transmission lines. In: 2012 11th international conference on environment and electrical engineering (EEEIC). IEEE, Venice, pp 53-58

Moravej Z, Pazoki M, Abdoos A (2011) A new approach for fault classification and section detection in compensated transmission line with TCSC. Int Trans Electr Energy Syst 21(1):997-1014

Moravej Z, Khederzadeh M, Pazoki M (2012) New combined method for fault detection, classification, and location in series-compensated transmission line. Electr Power Compon Syst 40(9):1050-1071

Nurdin M, Rahmani R, Hariyanto N, Armaini, Sasmono S, Faizal R (2012) Fix series capacitor for increasing power transfer on transmission $150 \mathrm{kV}$ at Sumatera interconnection system. In: 2012 international conference on condition monitoring and diagnosis (CMD), pp 565-568

Oliveira A (2008) The main aspects of fixed series compensation dimensioning at Brazilian $230 \mathrm{kV}$ transmission system. In: 2008 IEEE/PES transmission and distribution conference and exposition: Latin America, pp 1-9

Parikh U, Das B, Maheshwari R (2008) Combined wavelet-SVM technique for fault zone detection in a series compensated transmission line. IEEE Trans Power Deliv 23(4):1789-1794

Perven R, Kishor N, Mohanty S (2015) Fault detection and optimal coordination of overcurrent relay in offshore wind farm connected to onshore grid with VSC-HVDC. Int Trans Electr Energy Syst 26(4):841-863

Ray P (2014) Fast and accurate fault location by extreme learning machine in a series compensated transmission line. In: 2014 power and energy systems conference: towards sustainable energy (PESTSE). IEEE, pp 1-6

Ray P, Panigrahi B, Senroy N (2013) Hybrid methodology for fault distance estimation in series compensated transmission line. IET Gener Transm Distrib 7(5):431-439

Reddy M, Mohanta D (2007) A wavelet-neuro-fuzzy combined approach for digital relaying of transmission line faults. Electr Power Compon Syst 35:1385-1407

Reddy M, Mohanta D (2008) Adaptive-neuro-fuzzy inference system approach for transmission line fault classification and location incorporating effects of power swings. IET Gener Transm Distrib 2:235-244

Rubeena R, Zadeh M, Bains T (2014) An accurate offline phasor estimation for fault location in series-compensated lines. IEEE Trans Power Deliv 29(2):876-883

Vyas B, Maheshwari R, Das B (2014a) Protection of series compensated transmission line: issues and state of art. Electr Power Syst Res 107:93-108

Vyas B, Maheshwari R, Das B (2014b) Investigation for improved artificial intelligence techniques for thyristor-controlled series-compensated transmission line fault classification with discrete wavelet packet entropy measures. Electr Power Co. Syst 42(6):554-566

Yusuff A, Fei C, Jimoh A, Munda J (2011) Fault location in a series compensated transmission line based on wavelet packet decomposition and support vector regression. Electr Power Syst Res 81(7):1258-1265 